ENSINO E PESQUISA EM ADMINISTRAÇÃO 


\title{
USO FIEL DA FENOMENOLOGIA: UM FENOOMENO RARO?
}

\author{
CORRECT USE OF PHENOMENOLOGY: AN USUAL PHENOMENON?
}

\section{RESUMO}

A fenomenologia pode ser entendida como filosofia ou como método. Enquanto método, é útil na pesquisa organizacional e de consumo, já que possibilita a compreensão de questões intrincadas que podem não estar implícitas de forma imediata em respostas superficiais. Contudo, há consenso de que não se trata de algo trivial. Lançando mão de amostra de artigos de Administração, extraídos da base Spell, este artigo, qualitativo, que se caracteriza como levantamento bibliográfico, quanto aos meios, e descritivo-exploratório, quanto aos fins, investiga até que ponto os pesquisadores dessa área de fato utilizam corretamente o método fenomenológico em pesquisas empíricas. Sua conclusão é de que, além de poucos serem os artigos que se dizem fenomenológicos, uma proporção diminuta deles de fato cumpre as exigências para assim se qualificar. Reflexões são realizadas a respeito desse resultado e novas pesquisas são sugeridas.

\section{PALAVRAS-CHAVE}

Pesquisa Organizacional. Fenomenologia. Métodos de Pesquisa. 


\section{ABSTRACT}

Phenomenology can be understood as a philosophy or as a method. As a method it is useful in organizational and consumer research, as it allows the understanding of intricate issues that cannot be implied immediately with superficial answers. However, there is consensus that it is not something trivial. Through a sample of articles taken from Spell base, this qualitative article investigates the extent to which researchers use properly the phenomenological method in empirical research. It is concluded that, besides existing only a few articles that call themselves phenomenological, a tiny proportion of them actually meet the necessary requirements. This result is discussed, and further research is suggested.

\section{KEYWORDS}

Organizational Research. Phenomenology. Research Methods.

\section{INTRODUÇÃO}

A fenomenologia nasceu como filosofia a partir dos estudos de Husserl (1967, 200 I) no início do século $X X$. E, por mais que esse filósofo nunca se tenha disposto a desenvolvê-la como um método de realização de pesquisa empírica qualitativa, isso posteriormente aconteceu, fazendo com que a fenomenologia tenha passado a ser vista dessa forma dual.

Mas, se é verdade que "O método fenomenológico nasceu no contexto da especulação filosófica, e sua transposição para o conjunto da pesquisa empírica forçosamente cria problemas" (MOREIRA, 2004, p. 5), por outro lado, esse acontecimento - que o fez adquirir um nível de complexidade que o diferencia dos demais meios de pesquisa clássicos da abordagem qualitativa - Ihe trouxe benefícios. Isso porque o fez ser visto como útil na pesquisa organizacional e de consumo, já que possibilita a compreensão de questões intrincadas que podem não estar implícitas de forma imediata em respostas superficiais (GOULDING, 2005, p. 30I).

Por seu turno, essa dualidade traz, em si, a gênese de certa confusão. Frequentemente, quando se referem ao chamado "método fenomenológico", os autores em Administração "[...] estão simplesmente se referindo aos dados ou resultados obtidos, supostamente reais, profundos e que espelham melhor o fenômeno em estudo" (MOREIRA, 2004, p. 6).

Complementa essa constatação a não rara miscelânea de usos que os termos fenomenologia e fenomenológico costumam sofrer junto aos pesquisadores de Administração de Empresas:

Temos, portanto, os "resultados ou dados fenomenológicos", obtidos através do método da análise de conteúdo (MICK; DEMOSS, 1990; RUDMIN, 1994); "perspectiva ou abordagem fenomenológica", obtida ou não através de entrevistas (KLIOT, 1987; SPIVEY 
et al., 1997; SWINDER; TROCCHIA, 200I); "entrevista fenomenológica" (STERN; THOMPSON; ARNOULD, 1998); "clarificação fenomenológica" (SCHIPPER, 1999); "grupo de foco fenomenológico" (DURGEE, 1987); "investigação fenomenológica", usando video tapes de julgamentos criminais (LANZARA; PATRIOTTA, 200I), entre outros exemplos (MOREIRA, 2004, p. 6).

Além do mais, há um consenso acadêmico, na área de Administração, de que a fenomenologia e, por corolário, o método fenomenológico, não são triviais:

Como qualquer outro movimento filosófico, compreender a fenomenologia é tarefa árdua e exige muita dedicação em seu entendimento e em sua posterior utilização. Giorgi ( 1985 ) atribui a dificuldade do pensamento fenomenológico a três questões principais: (I) a de ir contra a tendência natural da consciência de dirigir-se às coisas em vez de a seus processos; (2) à evolução que o trabalho de Edmund Husserl, fundador da fenomenologia, teve durante toda a sua vida, além das alterações que se seguiram e ainda continuam; e (3) à incerteza quanto à consistência das interpretações dos discípulos de Husserl (SILVEIRA; GUERRA; GONÇALVES, 20I2, p. 270).

À luz desses elementos, é legítimo que surja uma especulação: até que ponto os pesquisadores da área de Administração de Empresas de fato utilizam corretamente o método fenomenológico em pesquisas empíricas? A resposta a essa pergunta se constitui no objetivo deste artigo, que é formado por quatro seções, além dessa introdução: referencial teórico, aspectos do método, resultados da pesquisa e conclusão.

\section{Referencial Teórico}

Fenomenologia, dependendo da posição epistemológica ou ontológica de quem se proponha a interpretar o termo, pode ser tanto uma filosofia como um método. No primeiro caso, estar-se-ia remetendo às obras de Husserl $(1962,1967)$ e de Heidegger (1962); no segundo caso, a gênese estaria em Schutz (1967).

Vista como filosofia, a fenomenologia defende que $o$ intelecto intui uma certeza sobre a essência das coisas, de forma imediata e absoluta. Para Husserl (1962, 1967), tratava-se de uma maneira nova de fazer filosofia, porque, ao dar destaque ao chamado mundo da vida - ou seja, ao mundo cotidiano, à experiência da vida, propunhase a entrar em contato diretamente com as chamadas coisas próprias.

Para tanto, deixavam-se de lado especulações metafísicas e abstratas: o fenômeno seria a informação que se apreende na consciência. Para a fenomenologia, o vento não interessa, mas sim a percepção que se tem dele quando bate no corpo (SILVEIRA; GUERRA; GONÇALVES, 20I2).

A proposta de Husserl $(1962,1967)$ partiu de uma vertente conhecida como fenomenologia descritiva ou transcendental, na qual a volta ao objeto foi suplementada por um retorno ao sujeito, e cujos conceitos mais importantes são: I) a essência, já que a concepção da fenomenologia remete a uma ciência de rigor, pura, das essências; 2) o imanente, correspondente ao que se vê; 3) o transcendente, que é a objetivação pessoal do imanente (ou seja, a transformação da simples imagem do objeto em 
significação do objeto), ocorrida por meio da análise intencional; e 4) a evidência apodítica, entendida como um saber certo e indubitável, necessário à construção de uma filosofia como ciência pura.

Assim é que "[...] a cadeira não é um fenômeno.A cadeira é o imanente.A objetivação ou a percepção da cadeira na consciência, feita na passagem do imanente para o transcendente, é que é o fenômeno" (SILVEIRA; GUERRA; GONÇALVES, 20I2, p. 279).

Fundamental para essa compreensão, e central na fenomenologia de Husserl (1962, 1967), é uma mudança na chamada atitude natural, a qual concebe o objeto como em si mesmo, independente da percepção. Em outras palavras, supõe que exista uma separação real entre o objeto e suas manifestações, assim como entende que a consciência é apreendida como uma região no interior da totalidade do mundo, limitada por outras regiões, o que supõe um exterior a si (MOURA, 1989).

Já na fenomenologia, tem-se a mudança dessa atitude, contida no conceito de redução, que se trata do

[...] momento em que são selecionadas as partes da descrição que são consideradas essenciais e aquelas que não o são, através da variação imaginativa. $O$ pesquisador imagina cada parte como estando presente ou ausente na experiência, até que a descrição seja reduzida ao essencial para a existência da consciência da experiência (CORREA, 1997).

Sem a redução, não se pode atingir a atitude filosófica fenomenológica:

A redução fenomenológica tem o objetivo de obter uma descrição conceitual rica da experiência na qual, deliberada e propositalmente, o pesquisador se abre para o fenômeno (GROENEWALD, 2004). Para buscar limitar o conhecimento ao fenômeno da experiência de consciência, procura desconsiderar o mundo real, em uma espécie de suspensão do juízo (MAISONNAVE; ROCHA PINTO, 2007, p. 92).

Essa redução apresenta duas vertentes: a fenomenológica e a eidética. Remetendo à suspensão do julgamento (em grego, epoché), a redução fenomenológica significa que, de forma radical, o filósofo deve "colocar entre parênteses”, ou seja, deixar de lado quaisquer opiniões, assim como suas crenças na tradição, nas ciências, e acerca da existência externa dos objetos (MOREIRA, 2004).

Já a redução eidética tem seu nome derivado da palavra grega para forma: eidos. Ela prega que o filósofo deve se mover "[...] da consciência de objetos individuais e concretos para o domínio transempírico das ciências puras" (MOREIRA, 2004, p. 9). Ao fazê-lo, ele atinge a intuição daquilo que existe na estrutura essencial e invariável de uma coisa, separado de tudo que lhe seja contingencial.

Voltando-se à fenomenologia enquanto método, ele se constitui na transposição da filosofia para a pesquisa empírica. Essa passagem se reveste de elevada importância no campo da Administração de Empresas, em particular dentro da área de Marketing, no que tange às experiências, intrinsecamente relacionadas ao fenômeno do consumo (AGUIAR; BARBOSA, 20I3):

A fenomenologia, além de ser concebida na sua origem como um movimento filosófico, é também compre- 
endida como método de investigação, devendo-se ter o cuidado para que essas premissas não sejam consideradas de maneira isolada. Ou melhor, não se deve considerar a pesquisa fenomenológica como um método especulativo, abstrato, monolítico, de caráter individual e utilitarista, mas sim como uma atitude existencial e filosófica, voltada para o mundo experiencial no qual a vivência humana é tida como algo constituído e constituinte daquilo que se denomina mundo ou espaço, onde se projeta e se constrói a realidade (DE PAULA;ANDRADE, 20I I, p. I58).

Por outro lado, como Husserl (1962, 1967) nunca propôs um método fenomenológico de realização de pesquisa empíri$c a$, há autores que entendem que " $A$ passagem da fenomenologia como filosofia para um método fenomenológico de pesquisa tem sido reivindicada por muitos pesquisadores, mas [...] [essa passagem] não fica muito clara" (SILVEIRA; GUERRA; GONÇALVES, 20I2, p. 270).

Uma proposta para essa transição vem de Moreira (2004), para quem ela só pode ser feita caso adaptações e concessões rigorosas sejam obedecidas, salientando-se duas. A primeira delas é que a aplicação do método fenomenológico só se deve dar em situações onde seja possível ter-se "[...] a experiência tal como se apresenta, e não o que possamos pensar, ler ou dizer acerca dela" (MOREIRA, 2004, p. I3). Assim, apenas se houver respostas positivas a três questões haverá a indicação da propriedade do uso do método fenomenológico (STREUBERT; CARPENTER, 1995): I) é necessária maior clareza no fenômeno estudado; 2) a experiência vivida e compartilhada é a melhor fonte de dados para o fenômeno de interesse; e 3) há adequação do pesquisador, do seu tempo disponível, dos seus recursos, do seu estilo pessoal, da sua habilidade e da sua audiência ao uso desse método. $O$ segundo requisito é que estejam presentes as duas reduções já mencionadas, assim como a descoberta das essências relacionadas ao fenômeno em estudo (MOREIRA, 2004).

Essa situação de adequação da fenomenologia ao traçado de um método, mas sempre subordinada a exigências, deu origem a algumas propostas de formalização do método, com ou sem a intenção específica de aplicação em fenômenos ligados ao consumo. Por exemplo, Giorgi (1985), Colaizzi (1978) e van Kaan (1959) enquadram-se como autores cujas propostas de método não tinham essa intenção.

Já no caso de autores que se dedicaram a propor método adequado a fenômenos ligados ao consumo, um exemplo recente é o de Aguiar e Barbosa (2013). Inspirado em Martins ( 1993) e em Bicudo (20I I), seu método apresenta detalhes consagrados às etapas de redução e de interpretação fenomenológicas, já que elaborado à luz da fenomenologia da percepção filosófica de Merleau-Ponty (2006). O olhar desse filósofo privilegiava a noção de que a redução fenomenológica não se poderia dar à sombra da retirada completa da subjetividade que possibilita a apreensão dos fenômenos: o que interessa é a exploração das "[...] vivências particulares em que os parâmetros perceptivos de organização dos dados são exercidos por um sujeito engajado nas situações do cotidiano" (AGUIAR; BARBOSA, 20I3, p. 6).

Outro exemplo menos recente de mo- 
delo de pesquisa fenomenológica adequada à área organizacional, e que tem sido assaz referenciado, é o de Sanders (1982). Essa autora colocou que haveria três componentes fundamentais no seu desenho, sendo os dois primeiros comuns a outros paradigmas científico-normativos assim como a outros modelos de pesquisa qualitativa:

I) O quê ou quem será objeto de investigação: a interpretação teórica da proposta de Husserl $(1962,1967)$ de que seja analisada "a coisa em si", e que poderia levar à conclusão de que qualquer coisa que tenha aparência ou consciência poderia ser analisada fenomenologicamente, deveria ser entendida, no caso da pesquisa organizacional fenomenológica, como sua adequação a assuntos que não sejam facilmente mensuráveis. Da mesma forma, os sujeitos selecionados - no mínimo três e no máximo seis - devem ser aqueles que têm as características que estão sendo analisadas ou que possam dar informações confiáveis sobre o fenômeno investigado.

2) O levantamento das evidências: há três tipos de técnicas de levantamento das evidências na técnica fenomenológica, sempre se levando em conta que é mais profícuo fazerem-se poucas perguntas, e explorá-las profundamente, do que achar que fazer muitas perguntas implicará mais evidências.A primeira técnica são as entrevistas em profundidade semiestruturadas, que devem ser gravadas e transcritas, considerando que a importância de se terem as palavras exatas dos entrevistados para estudo e análise posteriores, já que elas não sofrem a reinterpretação do pesquisador que uma anotação das respostas fatalmente implicaria. A segunda técnica - frequentemente utilizada em conjunto com a primeira - é a análise de evidências escritas pelos sujeitos pesquisados, de forma a descobrir-lhes significados. A terceira técnica é a observação participante, que implica algumas entrevistas para a exploração mais profunda de comportamentos particulares.

3) A análise fenomenológica das evidências: tendo em mente que, fiel à característica clássica da abordagem qualitativa de que seus resultados não se generalizam, essa análise se apresenta em quatro níveis, cada um deles servindo de resposta a uma pergunta que o pesquisador fenomenológico deve responder:

3.I) Como pode ser descrito o fenômeno ou a experiência investigada? A resposta encontra-se na descrição do fenômeno conforme ele se revela nas entrevistas gravadas: "As narrativas transcritas identificam e descrevem as qualidades da experiência e da consciência humanas, que dão, à pessoa que está sendo estudada, sua identidade e perspectiva únicas" (SANDERS, 1982, p. 357).

3.2) Quais os temas emergentes nessas descrições? A resposta encontra-se na identificação dos temas que emergem das descrições, definidos como elementos comuns tanto dentro das narrativas como entre narrativas. Sua identificação se dá muito mais com base na importância e na centralidade que detêm do que na frequência com que ocorrem.

3.3) Quais as reflexões subjetivas desses temas? Para a resposta, deve-se, primeiramente, ter em mente que noema refere-se ao "o quê" da experiência, e que noese refere-se ao "como" da experiência.A partir daí, a resposta vem do desenvolvimento dos correlatos noéticos-noemáticos, que são as 
reflexões subjetivas dos temas emergentes. Sanders (1982, p. 357) lança mão de um exemplo concreto ao explicar essa proposta:

"Meu chefe prefere que nos chamemos pelo primeiro nome. Isso faz com que eu me sinta importante e valorizada". A referência ao relacionamento baseado no primeiro nome entre superior e subordinada é uma afirmação objetiva e se constitui em um "noema". A afirmação de que isso faz a subordinada se sentir importante e valorizada é uma reflexão subjetiva da afirmação objetiva mencionada, e, portanto, constitui-se em uma "noese". Noético e noemático correlacionamse à percepção do indivíduo sobre a realidade do fenômeno que está sendo investigado. A interpretação dessas correlações é fundamental para a identificação das essências ou de o que uma experiência "é em essência".

\section{4) Quais as essências presentes nesses} temas e nas reflexões subjetivas? A resposta reside na abstração das essências a partir dos correlatos noéticos- noemáticos, o que se alcança por meio da intuição e da reflexão, ou da redução eidética. Trata-se do "por que" da experiência.

\section{Aspectos do Método}

A presente pesquisa qualifica-se como qualitativa no que diz respeito à abordagem, como descritivo-exploratória quanto à finalidade, e como levantamento bibliográfico no que tange aos meios (VERGA$\mathrm{RA}, 2013)$.

Dado que o objetivo foi avaliar até que ponto os pesquisadores da área de Ad- ministração de Empresas de fato utilizam corretamente o método fenomenológico em pesquisas empíricas, foram selecionados artigos da área de Administração de Empresas disponíveis na base Spell, da Associação Nacional de Pós-Graduação e Pesquisa em Administração (ANPAD), do período de janeiro 2010 a novembro 2015.

Esses artigos foram levantados por meio da ferramenta de busca automática da base, optando-se pela seleção daqueles que tivessem, no período visado, os termos "fenomenologia" ou "fenomenológico" ou "método fenomenológico" em seus respectivos resumos. A opção pela busca desses termos nos resumos deveu-se a duas suposições:

I) as boas práticas da redação de textos acadêmicos recomendam que nesse espaço sejam apresentadas as características mais relevantes do método adotado;

2) autores de Administração de Empresas que trabalham a fenomenologia costumam salientar essa opção no resumo do artigo (quando já não o fazem no seu próprio título), até por uma questão de orgulho acadêmico, visto tratar-se de método complexo:

Sabe-se que é uma tarefa bastante difícil e pouco comum a incursão do método fenomenológico no estudo dos fenômenos organizacionais, mas é também um desafio motivador e pode constituir-se num avançar no conhecimento de nuances até então desconhecidas ou pouco exploradas do mundo vivido nas empresas, visto que a investigação fenomenológica vai além da simples manifestação do fenômeno estudado (DE PAULA;ANDRADE, 20I I, p. I56). 
O resultado primário dessa busca foram 23 artigos, e uma primeira depuração buscou localizar aqueles derivados de pesquisas empíricas. Essa localização seguiu dois passos:

1) Leitura de seus respectivos títulos, que revelou o seguinte:

a) 10 apresentavam títulos que levavam a crer que se tratava de pesquisas empíricas;

b) quatro tinham títulos indistintos;

c) um não era da área de Administração;

d) três apresentavam títulos que remetiam a estudos sobre a fenomenologia em si, o que foi comprovado em seguida à leitura de cada um deles; e e) cinco apresentavam títulos que indicavam tratar-se de levantamentos sobre o uso da fenomenologia em estudos de Administração, o que foi comprovado em seguida à leitura de cada um deles.

Com isso, foram descartados os artigos dos três últimos itens, sobrando I4 para análise. No segundo passo, partiu-se para a leitura dos resumos dos quatro artigos cujos títulos eram indistintos, a fim de identificar sua ligação com a fenomenologia. $\mathrm{O}$ resultado dessa leitura foi que apenas um afirmava ter utilizado a fenomenologia para alcançar seu objetivo, enquanto os demais eram estudos sobre a fenomenologia.

Com isso, a seleção de artigos adequados à presente pesquisa foi reduzida a I I:Alvarenga e Pitombo (20 I5), Bazanini e Berton (20ll), Bazanini et al. (20l4), Costaito e Gimenez (20l2), Faria, Vergara e Carvalho (20|4), Macedo e Antonialli (20l3), Macedo et al. (20I2), Maravalhas e Odelius (2010), Simonetti e Silva
(20I3), Ventura e Leite (20I3) e Villardi e Vergara (20II).

Em seguida, foi definida a forma de avaliar se, de fato, nesses artigos teria havido o uso da fenomenologia enquanto método de pesquisa empírica. Isso foi feito à luz de Moreira (2004), para quem “A passagem direta de um método, da filosofia para a pesquisa empírica, por se tratarem de campos de reflexão tão diferentes, não poderá e não deverá dar-se de forma simples, sem concessões e adaptações" (p. I2), havendo duas questões relevantes nessa passagem:

I) que o método fenomenológico seja aplicado a tópicos em que "são recorrentes à experiência de vida de seres humanos: alegria ou medo, estar presente, estar envolvido, ser um gerente ou um líder, ou o sentido de algum tipo de experiência para pessoas num dado ambiente (pessoas numa instituição, por exemplo)" (MOREIRA, 2004, p. I3); e

2) que as duas reduções propostas pela filosofia - a fenomenológica e a eidética - estejam presentes de forma clara, prescindindo de inferências subjetivas, incluindo informações sobre como foram executadas.

No caso do segundo ponto acima, no presente levantamento definiu-se que haveria exceção no caso dos artigos que tivessem optado pela adoção da variante do método proposta por Sanders (1982). Em linha com que prega essa autora, seria suficiente a presença da redução eidética.

Para a avaliação do cumprimento - ou não - dessas exigências, foi lida a seção relativa ao método de cada um dos II artigos. $O$ resultado dessa leitura encontra-se a seguir.

\section{Resultados da Pesquisa}

Bazanini et al. (20I4) objetivaram identi- 
ficar as estratégias empregadas para a valorização da marca Corinthians, na perspectiva da estratégia de negócios empregada na gestão de um dirigente em especial. Ou seja, refere-se à experiência vivenciada. $A$ leitura da seção de aspectos do método identificou que o termo fenomenológico foi usado como sinônimo de qualitativo, sem que, de fato, tenha sido aplicado o método fenomenológico.

Simonetti e Silva $(20$ I 3, p.7) referiram-se à experiência vivenciada ao diagnosticarem a percepção dos moradores de uma cidade amazonense sobre os conflitos socioambientais gerados pelo turismo, e explicaram que seu encontro com a fenomenologia se deu enquanto orientação filosófica: "As orientações filosóficas que norteiam este estudo têm por base a fenomenologia, que é o estudo das essências, um relato do espaço, do tempo e do mundo experienciados [...]"

Ventura e Leite (20/4) referiram-se à experiência vivenciada ao investigarem as percepções de docentes do ensino superior acerca da influência da gestão estratégica de pessoas no comprometimento organizacional. Em seguida, uma primeira leitura de seus procedimentos metodológicos pareceu apontar na direção da real prática fenomenológica:

Baseando-se em Fachin (2003), optou-se pelo método fenomenológico, pois se pressupôs poder captar, com precisão, os aspectos essenciais do fenômeno em sua realidade. [...] A utilização de entrevistas com roteiro semiestruturado deve-se ao fato de que houve necessidade de revelar as motivações, atitudes, crenças e sentimentos sobre o fenômeno em estudo. [...] No que diz respeito às estratégias de análises dos dados [...] foram inspiradas, em especial, nos fragmentos coIhidos das mensagens nas entrevistas e nas observações, buscando-se os detalhes das características do conteúdo para formar as conclusões sobre - fenômeno estudado (VENTURA; LEITE, 20।4, p. I8- I9).

Contudo, aparentemente, Ventura e Leite (20l4) não passaram da intenção de se aventurarem no método fenomenológico, já que a simples busca pela palavra "redução" ao longo do texto resultou infrutífera.

Villardi eVergara (20 I I) se propuseram a pesquisar a forma como mestrandos aprendem, por meio de prática experiencial, a realizar pesquisa qualitativa em administração. Para tanto, buscaram entender a experiência vivida de professores e alunos, mas alertando que a fenomenologia as ajudou em nível iminentemente epistemológico:

A epistemologia na qual [a pesquisa delas] se fundamenta é a fenomenológica e, portanto, conforme apontaram Morgan e Smircich (1980) ao caracterizar esta vertente da pesquisa qualitativa, neste estudo também foram reconhecidas a subjetividade e intersubjetividade dos envolvidos [...] (VILLARDI;VERGARA, 201 I, p. 799).

Já o artigo de Faria,Vergara e CarvaIho (20I4) não se revelou empírico, apesar de o título sugerir essa possibilidade. Tratase de uma revisão bibliográfica que visa a refletir sobre alternativas à vertente epistemológica hegemônica em administração, representada pelo positivismo, incluindo a possibilidade de uso da epistemologia da fenomenologia. 
Também a pesquisa de Costaito e Gimenez (20 I 2, p. 237), apesar de o título sugerir essa possibilidade, não se revelou empírica, em seu objetivo de "[...] propor um framework hermenêutico, que utiliza uma abordagem fenomenológica, a ser aplicado na interpretação de textos organizacionais de um mesmo campo independentemente de pressupostos conflitantes, utilizando a aplicação na Estratégia como um exemplo".

Quanto aos demais cinco artigos, temse o seguinte:

I) Alvarenga e Pitombo (20I5, p. 92): com o objetivo de investigar o papel dos valores pessoais e organizacionais na escolha de carreira de jovens discentes trabalhadores em fases de planejamento e de início de carreira, adotaram a descrição de fotografias, cujos relatos foram tratados por análise de conteúdo visando a "identificar a essência dos relatos realizados a partir da categorização dos dados obtidos". Mais à frente, remetendo a Moreira (2004), os autores dizem que

A partir dessas fotografias e desses relatos buscou-se descrever as experiências vivenciadas e apresentadas por esses participantes, procurandose, em seguida, identificar a essência dos conteúdos, os temas e os elementos gerais presentes na amostra e, assim, iniciar a caracterização do fenômeno descrito (ALVARENGA; PITOMBRO, 20I5, p. 92).

Em vista desses elementos - que parecem apontar para a fenomenologia, já que se referem a experiências vivenciadas -, voltando-se aos dois requisitos que a presente pesquisa colocou como necessários para qualificar uma pesquisa como fenomenológica, houve adequação do tópico estu- dado ao método fenomenológico: parece razoável entender-se que a investigação do papel dos valores pessoais e organizacionais na escolha de carreira de jovens discentes trabalhadores em fases de planejamento e de início de carreira seja recorrente à experiência de vida de seres humanos. Já no que tange ao segundo requisito - que estejam presentes as duas reduções propostas pela filosofia - em hora alguma no artigo houve menção a elas.

2) Bazanini e Berton (20II): seu objetivo foi identificar as inovações e o empreendedorismo decorrentes das principais estratégias empregadas pela Ford do Brasil, no projeto e lançamento do veículo EcoSport, instrumentalizando o método fenomenológico por meio de entrevistas com especialista do mercado Off-Road, com executivos da Ford, com vendedores de concessionárias de automóveis próprias e com concorrentes. Pode-se entender, portanto, que foi obedecida a conveniência do método para o caso de um tipo de experiência para pessoas num dado ambiente. Além disso, os autores apresentam, em detalhes, as providências tomadas para garantir o atendimento às exigências do método fenomenológico, e expressamente referem-se à consecução das duas reduções.

3) Macedo e Antonialli (20/3): a pesquisa investiga os motivos presentes na ação estratégica desenvolvida por estrategistas no meio social do arranjo produtivo local moveleiro de Bento Gonçalves. Para tanto, os autores ressaltam ter utilizado a variante do método fenomenológico proposto por Sanders (1982). Pode-se entender que foi obedecida a conveniência do método para o caso de um tipo de experiência para pessoas num dado ambiente. Já no caso dos procedimentos de redução fe- 
nomenológica, na seção de apresentação e análise dos dados, após apresentarem oito unidades de sentido identificadas, os autores não são explícitos quanto à consecução da redução eidética; apenas dizem de forma sucinta "[...] sendo que as unidades de sentido são provenientes da redução fenomenológica, que versa a análise dos dados sem a pretensão de verificar qualquer tipo de hipótese" (MACEDO; ANTONIALLI, 20I3, p. 108).

4) Macedo et al. (20/2): com o objetivo de analisar como se processam as relações de gênero no contexto organizacional de uma empresa de extração mineral, os autores também utilizam a variante do método fenomenológico proposta por Sanders (I982). Pode-se entender que foi obedecida a conveniência do método para o caso de um tipo de experiência para pessoas num dado ambiente. Já no que tange à redução eidética, na seção de procedimentos de análise dos dados são feitas diversas referências à importância desse momento, e à forma como se deve proceder para tanto. Isso sugere que os autores quiseram dar a entender que, compreendendo a importância dessa etapa, a executaram, mas não informam detalhes a respeito.

5) Maravalhas e Odelius (20I0): o objetivo da pesquisa foi investigar a aprendizagem decorrente de mudanças geradas com a implementação de um novo modelo de atuação na auditoria interna de uma empresa do setor financeiro. Os autores utilizaram a variante do método fenomenológico proposta por Sanders (1 982). Pode-se entender que foi obedecida a conveniência do método para o caso de um tipo de experiência para pessoas num dado ambiente. Os autores também se preocuparam em informar, com alguns detalhes, a forma como executaram a redução fenomenológica eidética.

Os resultados dessa busca encontramse resumidos no Quadro I.

\section{Conclusão}

A primeira varredura realizada na base Spell indicou que, em período de seis anos, houve tão somente 23 artigos com os termos "fenomenologia" ou "fenomenológico" ou "método fenomenológico" em seus respectivos resumos - ou seja, média de menos de quatro artigos por ano. Intuitivamente, levando-se em consideração a abrangência dessa base, a quantidade de revistas qualificadas da área de Administração e o número de artigos que elas, em média, costumam publicar anualmente, pode-se inferir que é assaz reduzida a expressão, no total da produção científica da área, dessas pouco mais de duas dezenas de artigos.

No caso dos II artigos que foram objeto da análise central da presente investigação, viu-se que dois foram descartados por se ter identificado que não se tratavam de artigos empíricos, o que reduziu a amostra para nove artigos.

Esses remanescentes, por sua vez, apresentaram quatro subgrupos, com as seguintes respectivas características:

1) Fenomenológico usado como sinônimo de qualitativo: um artigo;

2) Utilização da fenomenologia em nível iminentemente epistemológico: um artigo;

3) Fenomenologia utilizada enquanto filosofia: um artigo;

4) Fenomenologia utilizada enquanto método: seis artigos.

Por seu turno, foi detectado que todos os seis artigos que utilizaram a fenomenolo- 
QUADRO 1 - Resumo dos resultados da pesquisa

\begin{tabular}{|c|c|c|c|}
\hline \multirow[b]{2}{*}{$\begin{array}{l}\text { Autores dos artigos } \\
\text { da amostra }\end{array}$} & \multirow[b]{2}{*}{$\begin{array}{l}\text { Utiliza a fenomenologia } \\
\text { como método ou como } \\
\text { filosofia? }\end{array}$} & \multicolumn{2}{|c|}{ Se a fenomenologia foi utilizada enquanto método } \\
\hline & & $\begin{array}{l}\text { Os tópicos visados são } \\
\text { adequados à aplicação do } \\
\text { método fenomenológico, } \\
\text { conforme Moreira (2004)? }\end{array}$ & $\begin{array}{l}\text { As reduções fenomenológica e eidética } \\
\text { - ou apenas a eidética quando adotado } \\
\text { o método de Sanders (1982) - estão pre- } \\
\text { sentes de forma clara, incluindo infor- } \\
\text { mações sobre como foram executadas? }\end{array}$ \\
\hline $\begin{array}{l}\text { Faria, Vergara e } \\
\text { Carvalho (2014) }\end{array}$ & \multicolumn{3}{|c|}{ As perguntas não se aplicam: o artigo não é empírico } \\
\hline $\begin{array}{l}\text { Costaito e Gimenez } \\
\qquad(2012)\end{array}$ & \multicolumn{3}{|c|}{ As perguntas não se aplicam: o artigo não é empírico } \\
\hline Bazanini et al. (2014) & \multicolumn{3}{|c|}{ As perguntas não se aplicam: o termo fenomenológico foi usado como sinônimo de qualitativo } \\
\hline $\begin{array}{l}\text { Villardi e Vergara } \\
\qquad(2011)\end{array}$ & \multicolumn{3}{|c|}{ As perguntas não se aplicam: a fenomenologia foi utilizada em nível iminentemente epistemológico } \\
\hline $\begin{array}{l}\text { Simonetti e Silva } \\
\text { (2013) }\end{array}$ & Como filosofia & & \\
\hline $\begin{array}{l}\text { Bazanini e Berton } \\
\qquad(2011)\end{array}$ & Como método & Sim & $\begin{array}{l}\text { Sim; os autores apresentam, em detalhes, } \\
\text { as providências tomadas para garantir o } \\
\text { atendimento às exigências do método feno- } \\
\text { menológico, e expressamente referem-se à } \\
\text { consecução das duas reduções. }\end{array}$ \\
\hline $\begin{array}{l}\text { Maravalhas e Ode- } \\
\text { lius (2010) }\end{array}$ & Como método & Sim & $\begin{array}{l}\text { Sim; os autores informam, com alguns de- } \\
\text { talhes, a forma como executaram a redução } \\
\text { fenomenológica. }\end{array}$ \\
\hline $\begin{array}{l}\text { Macedo e Antonialli } \\
\qquad(2013)\end{array}$ & Como método & Sim & $\begin{array}{l}\text { Os autores não são explícitos quanto à } \\
\text { consecução da redução eidética; apenas } \\
\text { dizem de forma sucinta "[...] sendo que as } \\
\text { unidades de sentido são provenientes da } \\
\text { redução fenomenológica, que versa a aná- } \\
\text { lise dos dados sem a pretensão de verificar } \\
\text { qualquer tipo de hipótese" (p. 108). }\end{array}$ \\
\hline Macedo et al. (2012) & Como método & Sim & $\begin{array}{l}\text { Está sugerido que os autores compreendem } \\
\text { a importância dessa etapa e que a executa- } \\
\text { ram, mas não informam detalhes a respeito. }\end{array}$ \\
\hline $\begin{array}{l}\text { Ventura e Leite } \\
\qquad(2014)\end{array}$ & Como método & Sim & $\begin{array}{l}\text { Não; a palavra "redução" nem é menciona- } \\
\text { da no texto. }\end{array}$ \\
\hline $\begin{array}{l}\text { Alvarenga e Pitombo } \\
\qquad(2015)\end{array}$ & Como método & Sim & $\begin{array}{l}\text { Não; a palavra "redução" nem é menciona- } \\
\text { da no texto. }\end{array}$ \\
\hline
\end{tabular}

Fonte: Elaboração própria.

gia enquanto método apresentaram tópicos adequados à aplicação do método fenomenológico (MOREIRA, 2004); por outro lado apenas dois apresentaram as reduções fenomenológica e eidética - ou apenas a eidética quando adotado o método de Sanders (1982) - de forma clara, incluindo informações sobre como elas foram executadas.
Essa evidência suscita uma pergunta:por que a redução fenomenológica é tão pouco visível em estudos que usam o método fenomenológico, considerando que ela é "[...] necessária, segundo Husserl, para que se consiga atingir a atitude filosófica ou fenomenológica" (MOREIRA, 2004, p. 9)?

É possível especular duas respostas a 
essa pergunta: os autores realizaram a redução, mas falharam em mencioná-la de forma explícita; ou os autores, de fato, não realizaram a redução. Realizar a redução sem mencionar tê-la feito sinalizaria um desconhecimento quanto ao peso que tal procedimento exerce no método - o que, em última análise, implica desconhecimento quanto ao método em si.

Por outro lado, não realizar a redução é preocupante, tendo em vista a importância dessa etapa em estudos fenomenológicos: sem ela, simplesmente não se pode qualificar dessa forma uma pesquisa científica. Seguindo-se essa lógica, conclui-se que Ventura e Leite (2014) e Alvarenga e Pitombo (20I5) não teriam, de fato, realizado pesquisas fenomenológicas.

Por sua vez, isso levanta a seguinte questão: se não chegaram, de fato, a realizar pesquisa fenomenológica, por que disseram terem-no feito? Talvez isso tenha ocorrido por um mero desconhecimento, por parte dos autores, quanto às especificidades do procedimento reducionista, tendo em vista que se trata de "[...] um dos conceitos mais complexos e controversos para a noção da fenomenologia de Edmund Husserl" (SILVEIRA; GUERRA; GONÇALVES, 20I2, p. 280).

Ou, ainda, talvez a razão seja ainda maior, remetendo ao que reconheceram De Paula e Andrade (20l I): a incursão do método em si no estudo dos fenômenos organizacionais é tarefa bastante difícil. Caso essa tenha sido a razão, vale notar que essa distorção não seria fenômeno isolado: também no caso da grounded theory não é incomum encontrá-la (TROCCOLI, 20I4). De fato, o paralelismo entre os dois casos que aqui se mostra muito adequado:

[...] as raízes da opção pelo uso da GT [grounded theory] frequentemente se perdem em uma espécie de deslumbramento dos pesquisadores quanto à perspectiva de virem a criar teoria. Em outras palavras, é como se uma leitura viesada dos princípios originais da GT propostos por Glaser e Strauss (1967) fosse deliberadamente adotada por pesquisadores que afirmam praticar a técnica (embora na verdade não consigam fazê-lo), como forma de alimentar-lhes o ego. Afinal, a GT não é fácil (SUDDABY, 2006, apud TROCCOLI, 20I4, p. 34).

Outro aspecto que não deve deixar de ser mencionado como conclusão é o que se verificou junto a Macedo e Antonialli (20l3) e a Macedo et al. (20I2). Em ambos os casos, os autores sugerem terem realizado a redução eidética, mas se eximem de informar detalhes a respeito. Essa postura pode ser entendida de duas formas: a importância da redução não foi plenamente compreendida, ou há o entendimento de que sua dificuldade intrínseca (SILVEIRA; GUERRA; GONÇALVES, 20I2) pode ser transposta, ao fim e ao cabo, por um mero desinteresse quanto ao seu tratamento:"desconsidere-o e ninguém vai notar sua falta”.

Finalmente, vale notar que os artigos de Macedo e Antonialli (2013), de Macedo et al. (20I2), de Ventura e Leite (20l4) e de Alvarenga e Pitombo (2015) foram publicados em revistas qualificadas - respectivamente situadas atualmente nos extratos B2, A2, B3 e B2 - da área de Administração. É sabido que essa aceitação depende de avaliação rigorosa em sistema de blind review, que inclui todos os aspectos da pesquisa, inclusive aqueles referentes ao método seguido.

Portanto, aparentemente, essa avaliação 
prescindiu de maior rigor no que tange aos procedimentos inerentes ao método fenomenológico. Essa tolerância, por sua vez, deveria ser questionada, até mesmo pela já mencionada própria dificuldade intrínseca à fenomenologia. Qual o avanço científico trazido pela explicação daquilo que é fácil?

O presente levantamento se restringiu a artigos presentes em uma base de pesqui- sas restritos a intervalo formado por seis anos. Seria interessante que fosse replicado em outras amostras - por exemplo, artigos dos Encontros da Associação Nacional de Pós-Graduação e Pesquisa em Administração (ENANPADs), ou de periódicos situados nas mais elevadas qualificações - de forma a confirmar, ou refutar, a tendência aqui encontrada. 


\section{REFERÊNCIAS}

AGUIAR, E.; BARBOSA, O. Fenomenologia da percepção: uma abordagem para a investigação de experiências de consumo. In: ENCONTRO DE ENSINO E PESQUISA EM ADMINISTRAÇÃO E CONTABILIDADE (EnEPQ), 4., 2013, Brasília. Anais... Brasília (DF): ENEPQ, 2013.

ALVARENGA, M.; PITOMBO, N. O papel dos valores nas escolhas de carreira de jovens discentes/ trabalhadores. Gestão \& Regionalidade, [S. I.], v. 3 I, n. 92, p. 86I02, 2015.

BAZANINI, R.; BERTON, R. Estratégias e geração de vantagem competitiva no mercado de veículos off-road: análise fenomenológica do lançamento do modelo Ford Ecosport no Brasil. REMark Revista Brasileira de Marketing, São Paulo, v. I0, n. I, P I23I50, 20II.

BAZANINI, R.;SANTOS, R.; RIBEIRO, H.; BAZANINI, H. Empreendedorismo na sociedade do espetáculo: gestão do futebol no universo globalizado. Perspectivas em Gestão \& Conhecimento, [S. I.], v. 4, n. I, p. I35-I60, 20 I4.

BICUDO, M. A. V. Pesquisa qualitativa segundo a visão fenomenológica. São Paulo: Cortez, $201 \mathrm{I}$.

COLAIZZI, P. Reflections and research in psychology: A phenomenological study of learning. Dubuque, IA: Kendall/Hunt, 1978.

CORREA, A. Fenomenologia: uma alternativa para pesquisa em enfermagem. Rev.latino-am.enfermagem, [S. I.], v. 5, n. I, p. 83-88, jan. 1997.

COSTAITO, N.; GIMENEZ, F. Interpretando textos organizacionais: um enfoque metodológico para a aplicação de uma hermenêutica fenomenológica de textos de estratégia. Administração: Ensino e Pesquisa, [S. I.], v. I3, n. 2, p. 237-268, 2012.

DE PAULA, R.; ANDRADE, J. A fenomenologia de Schutz nos estudos organizacionais: o caso da estratégia empresarial. REBRAE - Revista Brasileira de Estratégia, [S. I.], v. 4, n. 2, p. I55- I68, 20 I I.

DURGEE, J. F. Point of View: Using Creative Writing Techniques in Focus Groups. Journal of Advertising Research, [S. I.], v. 26, n. 6, p. 57-65, 1987.

FACHIN, O. Fundamentos de metodologia. 4. ed. São Paulo: Saraiva, 2003.

FARIA, M.; VERGARA, S.; CARVALHO, J. Pesquisas com foco em pessoas com deficiência no campo da administração: paradigmas e perspectivas epistemológicas. $\mathbf{R e}$ vista Gestão e Planejamento, [S. I.], v. I5, n. I, p. 2I-39, 20 I4.

GIORGI, A. Phenomenology and psychological research. Pittsburg: Duquesne University Press, 1985.

GLASER, B.; STRAUSS, A. The discovery of Grounded Theory. Chicago:Aldine 1967.

GOULDING, C. Grounded theory, ethnography and phenomenology. A comparative analysis of three qualitative strategies for marketing research. European Journal of Marketing, [S. I.], v. 39, n. 3-4, p. 294-308, 2005.

HEIDEGGER, M. Being and Time. New York, NY: Harper \& Row, 1962.

HUSSERL, E. The crisis of European Sciences and Transcendental Phenomenology. Evanston, IL: Northwestern University Press, 1962.

HUSSERL, E. Investigaciones lógicas. Madri: Castilha, 1967.
HUSSERL, E. A ideia da fenomenoIogia. Lisboa: Edições 70, $200 \mathrm{I}$.

KLIOT, N. Here and There:The Phenomenology of Settlement Removal from Northern Sinai. The Journal of Applied Behavioral Science, [S. I.], v. 23, n. I, p. 35-5I, 1987.

LANZARA, G. F; PATRIOTTA, G. Technology and the courtroom: An inquiry into knowledge making in organizations. The Journal of Management Studies, [S. I.], v. 38, n. 7, p. 943-97I, 200 I.

MACEDO, F.; ANTONIALLI, L. Estudo fenomenológico social da ação estratégica em um arranjo produtivo local moveleiro. Revista Ibero-Americana de Estratégia - RIAE, [S. I.], v. I2, n. 3, p. 93-124, 2013.

MACEDO, F.; BOAVA, D.; CAPPELLE, M.; OLIVEIRA, M. Relações de Gênero e Subjetividade na Mineração: um Estudo a partir da Fenomenologia Social. RAC, [S. I.], v. I6, n. 2, art. 3, p. 2I7-236, 2012.

MAISONNAVE, P.; ROCHA PINTO, S. Em busca da epoché: uma pesquisa quantitativa como subsídio à redução fenomenológica. RAI - Revista de Administração e Inovação, [S. I.], v. 4, n. 3, p. 86I0I, 2007.

MARAVALHAS, E.; ODELIUS, C. Aprendizagem e sensemaking em práticas de auditoria interna. Contabilidade, Gestão e Governança, [S. I.], v. I3, n. 3, p. I737, 2010.

MARTINS J. Um enfoque fenomenológico do currículo: a educação como poiesis. São Paulo: Cortez, 1993.

MERLEAU-PONTY, M. Fenomenologia da percepção. São Paulo: Martins Fontes, 2006.

MICK, D. G.; DEMOSS, M. Self-Gifts: 
Phenomenological Insights from Four Contexts. Journal of Consumer Research, [S. I.], v. 17, n. 3, p. 322-332, 1990.

MOREIRA, D. Pesquisa em Administração: origens, usos e variantes do método fenomenológico. RAI

- Revista de Administração e Inovação, [S. I.], v. I, n. I, p. 5-19, 2004.

MORGAN, G.; SMIRCICH, L. The case for qualitative research. The Academy of Management Review, [S. I.], v. 5, n. 4, p. 49I-500, 1980.

MOURA, C. Crítica da razão na fenomenologia. São Paulo: EDUSP, 1989.

RUDMIN, F. W. Gender Differences in the Semantics of Ownership: A Quantitative Phenomenological Survey Study. Journal of Economic Psychology, [S. I.], v. I5, n. 3, p. 487- 510, 1994.

SCHIPPER, F. Phenomenology and the Reflective Practitioner. Management Learning, [S. I.], v. 30, n. 4, p. 473-485, 1999.

SCHUTZ, A. The Phenomenology of the Social World. Evanston, IL: Northwestern University Press, 1967.

SILVEIRA, R.; GUERRA,A.; GONÇALVES, C.A aplicação da fenomenologia nos estudos organizacionais no Brasil. Administração: Ensi- no e Pesquisa, [S. I.], v. 13, n. 2, jun. p. 269-300, 2012.

SIMONETTI, S.; SILVA, G. Percepção dos conflitos socioambientais gerados pelo turismo na vila de $\mathrm{Pa}$ ricatuba (Iranduba-AM). Desafio Online, [S. I.], v. I, n. 2, 2013.

SPIVEY, W.; MUNSON, J.; NELSON, M.; DIETRICH, G. Coordinating the Technology Transfer and Transition of Information Technology: A Phenomenological Perspective. IEEE Transactions on Engineering Management, [S. I.], v. 44, n. 4, p. 359-366, 1997.

SPLITTER, K.; ROSA, C.; BORBA, J. Uma Análise das Características dos Trabalhos "Ditos" Bibliométricos Publicados no Enanpad entre 2000 e 201 I. In: CONGRESSO BRASILEIRO DE CUSTOS, 20., 2013, Uberlândia. Anais... São Leopoldo: Associação Brasileira de Custos, 2013.

STREUBERT, H.; CARPENTER, D. Qualitative Research in Nursing: Advancing the Humanistic Imperative. Philadelphia: J. B. Lippincott Company, 1995.

SUDDABY, R. From the editors: what grounded theory is not. Academy of Management Journal, [S. I.], v. 49, n. 4, p. 633-642, 2006.

SWINDER, J.; TROCCHIA, P. J. Vegetarianism: Toward a greater understanding. Psychology and
Marketing, [S. I.], v. 18, n. 12, p. I205- I240, 200 I.

STERN, B. B.; THOMPSON, C. J.; ARNOULD, E. J. Narrative analysis of a marketing relationship:The consumer's perspective. Psychology and Marketing, [S. I.], v. I5, n. 3, p. 195-2।4, 1998.

TROCCOLI, I. R. E os pesquisadores brasileiros que praticam grounded theory: o que fazem? Revista Digital de Biblioteconomia e Ciência da Informação, [S. I.], v. 12, p. 20-37, 2014.

VAN KAAN, A. Phenomenological analysis: Exemplified by a study of the experience of "really feeling understood”. Journal of Individual Psychology, [S. I.], v. I5, p. 66-72, 1959.

VENTURA, V.; LEITE, N. Percepção da influência da gestão estratégica de pessoas no comprometimento organizacional. PRETEXTO, Belo Horizonte, v. I5, n. 3, p. II28, 2014.

VERGARA, S. C. Projetos e relatórios de pesquisa em administração. São Paulo:Atlas, 2013.

VILLARDI, B.; VERGARA, S. Implicações da Aprendizagem Experiencial e da Reflexão Pública para o Ensino de Pesquisa Qualitativa e a Formação de Mestres em Administração. RAC, Curitiba, v. I5, n. 5, art. I, p. 794-8 I4, 20 I I. 